eISSN: 2655-8688

http://jurnal.stikes-sitihajar.ac.id/index.php/jhsp hal: 100-105
pISSN: 2548-3943

received Mei, Accepted Mei, Publish Juni

Volume 1, Nomor 2 - 2019

Copyright @2019. This is an open-access arcle distributed under the terms of the CreaveCommons A
nc-sa/4.0/which permits unrestricted non-commercial used, distribuon and reproducon in any medium

\title{
Perilaku Remaja Putri dalam Perawatan Kebersihan Alat Reproduksi Pada Saat Mensturasi di SMP Swasta Al-Hikmah Wilayah Marihat Bandar Kabupaten Simalungun
}

\author{
Lismawati $^{1}$ \\ ${ }^{1}$ Akademi Keperawatan Kesdam I/BB Pematangsiantar \\ Email: akperkesdam.siantar@ gmail.com
}

\begin{abstract}
ABSTRAK
Menstruasi terjadi pada anak putri ketika masa pubertas telah tiba. Tujuan penelitian adalah untuk mengetahui Perilaku Remaja putri dalam Perawatan Kebersihan Alat Reproduksi Pada Saat Menstruasi. Metode Penelitian ini menggunakan deskriptif dengan teknik pengambilan sempel secara total sampling. Jumlah responden sebanyak 40 orang. Dari hasil penelitian menunjukan bahwa pengetahuan responden dengan mayoritas responden berpengetahuan baik sebanyak 32 responden (80\%), berpengetahuan cukup sebanyak 8 responden (8\%), dan berpengetahuan kurang sebanyak 0 responden $(0 \%)$. Mayoritas yang memiliki sikap Positif sebanyak 29 responden (72,5\%), sikap Negatif sebanyak 11 responden (27,5\%). Mayoritas yang memiliki tindakan dilakukan sebanyak 29 responden $(72,5 \%)$, tindakan tidak dilakukan sebanyak 11 responden (27,5\%). Untuk itu kepada siswi SMP Swasta AL-HIKMAH Wilayah Marihat Bandar Kabupaten Simalungun banyak membaca dan belajar mengenai persoalan perawatan kebersihan alat reproduksi pada saat menstruasi ini lewat buku atau media.
\end{abstract}

Kata kunci: Menstruasi, Remaja Putri, Perilaku

\section{Adolescent Girls' Behavior in Reproductive Hygiene Care during Menstruation at Al- Hikmah Private Middle School, Marihat Bandar District}

\begin{abstract}
Menstruation occurs in a daughter when puberty has arrived. The study aimed to find out the Adolescent Girls' Behavior in Reproductive Hygiene Treatment at Menstruation. This research method uses a descriptive technique with total sampling. The number of respondents is 40 people. The results of the study show that the knowledge of respondents with the majority of respondents knowledgeable as many as 32 respondents (80\%), knowledgeable enough as many as eight respondents (8\%), and less known as much as 0 respondents (0\%). The majority who have positive attitudes are 29 respondents (72.5\%), negative attitudes are 11 respondents (27.5\%). The majority of those who had actions were 29 respondents (72.5\%); the actions not taken as many as 11 respondents (27.5\%). For this reason, students in AL-HIKMAH Private Middle School, Marihat Bandar District, Simalungun District, have read and learned a lot about the maintenance issues of reproductive hygiene during menstruation through books or media.
\end{abstract}

Keyword: menstruation, Adolescent Girls, Behavior 


\section{Pendahuluan}

Mighwar (2006) mendefinisikan arti kata remaja atau yang dikenal dengan adolescence sebagai tumbuh, yang diambil dari bahasa latin adolescere. Mighwar juga menjelaskan tumbuh disini adalah proses pertumbuhan kematangan psikis dan fisik seseorang. Kematangan psikis diitandai dengan matangnya kondisi kejiwaan, pikiran, dan emosi. Sedangkan kematangan fisik, seperti yang dipercayai oleh orangorang kuno, pada fase remaja organ reproduksi seorang anak telah matang seperti orang dewasa (Sessa, 2015) (Thapar, Collishaw, Pine, \& Thapar, 2012) (Viner et al., 2012).

Depkes (2001:3) menyatakan bahwa sistem reproduksi yang sehat adalah organ-organ reproduksi yang berfungsi dengan baik dalam proses reproduksi. Lebih lanjut, Widyastuti (2009) menyatakan para remaja membutuhkan ilmu kesehatan reproduksi dalam bentuk program kesehatan reproduksi bagi remaja agar mereka sadar akan pentingnya menjaga kesehatan reproduksi (BKKBN, 2013).

Pada tahun 2009, Pinem mengemukakan bahwa para remaja memiliki pengetahuan yang rendah tentang kesehatan reproduksi, yaitu kurang dari 30 $\%$ remaja laki-laki dan perempuan mengetahui ada perubahan pada fisik lawan jenisnya. Ketidaktahuan remaja terhadap perubahan organ-organ tubuh mereka mengindikasikan rendahnya pengetahuan mereka terhadap akibat buruk jika mereka tidak memerhatikan kesehatan reproduksi mereka, begitu juga pencegahannya (Manuaba, 2010).

Menurut WHO (World Health Organization) seorang dikategorikan sebagai remaja ketika ia berada pada rentang usia 10 -19 tahun, atau disebut dengan masa adolescence. Baradero (2007) mengatakan bahwa umumnya pada usia 10 - 16 tahun remaja putri akan mengalami 'menarche', yaitu haid atau menstruasi pertama. Selama haid, vagina harus dibersihkan secara rutin agar terhindar dari bakteri Candida albican, Trichomonas vaginalis dan Gardnella vaginalis yang dapat mengakibatkan penyakit saluran reproduksi seperti pruritus vulva, iritasi, inflamasi, sekresi vaginal dan rasa perih (Farizal \& Dewa, 2017) (Alli J.A.O., Okonko I.O, Odu N.N., 2011). Bakteribakteri tersebut mudah sekali masuk karena pada saat haid pembuluh darah pada rahim mudah terinfeksi (Septadina \& Seta, 2015).

Membersihkan vagina secara rutin dan teratur adalah salah satu upaya awal dari merawat organ reproduksi wanita. Kita perlu membersihkan keringat dan bakteri pada bibir vagina (vulva) dengan air bersih dan sabun. Selain itu, Kissanti (2008: 22) menuturkan pada saat haid tindakan mengganti pembalut $4-5$ kali dalam sehari juga diperlukan sebagai tindakan preventif dari risiko penyakit yang diakibatkan masuknya bakteri-bakteri itu ke dalam vagina (Larasati \& Alatas, 2016). Sayangnya, berdasarkan penilitian yang dilakukan Daiyah pada tahun 2004, hanya 15 dari 58 remaja yang memahami perawatan organ reproduksi bagian luar dengan baik. Angka yang masih cukup rendah.

Pada tahap awal penilitian, peneliti melakukan survey terhadap 10 siswa remaja putri yang sudah mengalami menstruasi di SMP Swasta Al Hikmah Marihat Bandar Kabupaten Simalungan. Dari survey tersebut ditemukan hanya tiga remaja yang memahami cara membersihkan organ reproduksi dengan benar, seperti tindakan mengganti pembalut 2 kali dalam sehari, sedangkan 7 lainnya tidak membersihkan organ reproduksi dengan benar karena kurangnya pengetahuan mereka tentang cara membersihkan organ reproduksi saat menstruasi.

\section{Metode Penelitian}

Penelitian ini menggunakan desain Deskriptif. Sampel menggunakan Total Sampling dan didapatkan 40 orang. Lokasi penelitian berada SMP Swasta Al-Hikmah Marihat Bandar Kabupaten Simalungun dan dilakukan pada bulan Juni 2018. 


\section{Hasil Penelitian}

Tabel 1 Distribusi frekwensi dan persentase responden berdasarkan data demografi

\begin{tabular}{|c|l|l|l|}
\hline No & \multicolumn{1}{|c|}{ Karakteristik responden } & Frekuensi & \multicolumn{1}{c|}{ Persentase \% } \\
\hline 1 & Umur (Tahun) & 13 & 32,5 \\
& $11-12$ & 16 & 40 \\
& $13-14$ & 11 & 27,5 \\
\hline & $15-16 \quad$ Total & 40 & $100 \%$ \\
\hline 2 & Kelas & 10 & \\
& I SMP & 14 & 25 \\
& II SMP & 16 & 35 \\
& III SMP & 40 & 40 \\
\hline & \multicolumn{2}{|c|}{ Total } & $100 \%$ \\
\hline
\end{tabular}

Table 2 Distribusi responden berdasarkan jawaban terhadap kuisioner mengenai pengetahuan perempuan dalam perawatan kebersihan alat reproduksi pada saat menstruasi

\begin{tabular}{|c|c|c|c|}
\hline No & Pernyataan & Benar & Salah \\
\hline 1. & $\begin{array}{l}\text { Mnstruasi atau haid merupakan pengeluaran darah dan } \\
\text { sel-sel tubuh secara periodik dari vagina yang berasal } \\
\text { dari dinding rahim. }\end{array}$ & $\begin{array}{c}39 \\
(90 \%)\end{array}$ & $\begin{array}{c}4 \\
(10 \%)\end{array}$ \\
\hline 2. & Menarche merupakan nyeri menstruasi (haid). & $\begin{array}{c}15 \\
(37,5 \%)\end{array}$ & $\begin{array}{c}25 \\
(62,5 \%) \\
\end{array}$ \\
\hline 3. & $\begin{array}{l}\text { Menstruasi pada setiap wanita terjadi pada usia } 10-14 \\
\text { tahun. }\end{array}$ & $\begin{array}{c}38 \\
(95 \%)\end{array}$ & $\begin{array}{c}2 \\
(5 \%)\end{array}$ \\
\hline 4. & Masa menstruasi seseorang terjadi sekitar 4-7 hari. & $\begin{array}{c}39 \\
(97,5 \%)\end{array}$ & $\begin{array}{c}1 \\
(2,5 \%)\end{array}$ \\
\hline 5 & $\begin{array}{l}\text { Lemas, keputihan, sakit perut, sakit pinggang jerawatan } \\
\text { tidak merupakan efek dari menstruasi (haid). }\end{array}$ & $\begin{array}{c}15 \\
(37,5 \%)\end{array}$ & $\begin{array}{c}25 \\
(62,5 \%)\end{array}$ \\
\hline 6. & Siklus menstruasi terjadi setiap 26-30 hari. & $\begin{array}{c}33 \\
(82,5 \%)\end{array}$ & $\begin{array}{c}7 \\
(17,5 \%)\end{array}$ \\
\hline 7. & $\begin{array}{l}\text { Mengkonsumsi tablet zat besi dapat mencegah terjadinya } \\
\text { anemia pada saat mestruasi. }\end{array}$ & $\begin{array}{c}32 \\
(80 \%)\end{array}$ & $\begin{array}{c}8 \\
(20 \%)\end{array}$ \\
\hline 8. & $\begin{array}{l}\text { Pada saat menstruasi dinding rahim terluka sehingga } \\
\text { rahim tidak mudah terkena infeksi.. }\end{array}$ & $\begin{array}{c}3 \\
(7,5 \%)\end{array}$ & $\begin{array}{c}37 \\
(92,5 \%)\end{array}$ \\
\hline 9. & Jumlah darah yang hilang biasanya $20-80 \mathrm{ml}$. & $\begin{array}{c}20 \\
(50 \%)\end{array}$ & $\begin{array}{c}20 \\
(50 \%)\end{array}$ \\
\hline 10. & $\begin{array}{l}\text { Mudah marah, tidak bersemangat, malas, nafsu } \\
\text { meningkat, tidak merupakan efek dari menstruasi (haid). }\end{array}$ & $\begin{array}{c}15 \\
(37,5 \%)\end{array}$ & $\begin{array}{c}25 \\
(62,5 \%)\end{array}$ \\
\hline
\end{tabular}


Table 3 Distribusi responden berdasarkan jawaban terhadap kuisioner mengenai sikap perempuan dalam perawatan kebersihan alat reproduksi pada saat menstruasi

\begin{tabular}{|c|c|c|c|c|c|}
\hline No & Pernyataan & SST & ST & KS & TS \\
\hline 1. & $\begin{array}{l}\text { Selalu makan banyak pada saat } \\
\text { menstruasi. }\end{array}$ & $\begin{array}{c}11 \\
(27,5 \%)\end{array}$ & $\begin{array}{c}18 \\
(45 \%)\end{array}$ & $\begin{array}{c}4 \\
(10 \%)\end{array}$ & $\begin{array}{c}6 \\
(15 \%)\end{array}$ \\
\hline 2. & $\begin{array}{l}\text { Pemakaian pembalut dapat memiliki } \\
\text { dampak negative }\end{array}$ & $\begin{array}{c}4 \\
(10 \%)\end{array}$ & $\begin{array}{c}19 \\
(47,5 \%)\end{array}$ & $\begin{array}{c}3 \\
(7,5 \%)\end{array}$ & $\begin{array}{c}14 \\
(35 \%)\end{array}$ \\
\hline 3. & $\begin{array}{l}\text { Saat menggunakan pembalut terjadi } \\
\text { iritasi kulit pada sekitar alat reproduksi }\end{array}$ & $\begin{array}{c}4 \\
(10 \%)\end{array}$ & $\begin{array}{c}10 \\
(25 \%)\end{array}$ & $\begin{array}{c}8 \\
(20 \%)\end{array}$ & $\begin{array}{c}18 \\
(45 \%)\end{array}$ \\
\hline 4. & $\begin{array}{l}\text { Saat mentruasi tiba pasti kita merasa } \\
\text { nyaman dan bebes braktifitas. }\end{array}$ & $\begin{array}{c}2 \\
(5 \%)\end{array}$ & $\begin{array}{c}3 \\
(7,5 \%)\end{array}$ & $\begin{array}{c}0 \\
(0 \%)\end{array}$ & $\begin{array}{c}35 \\
(87,5 \%)\end{array}$ \\
\hline 5. & $\begin{array}{l}\text { Mengikuti langkah-langkah yang benar } \\
\text { dalam merawat kebersihan alat } \\
\text { reproduksi pada saat menstruasi. }\end{array}$ & $\begin{array}{c}28 \\
(70 \%)\end{array}$ & $\begin{array}{c}10 \\
(25 \%)\end{array}$ & $\begin{array}{c}1 \\
(2,5 \%)\end{array}$ & $\begin{array}{c}1 \\
(2,5 \%)\end{array}$ \\
\hline 6. & $\begin{array}{l}\text { Penggunaan handuk orang lain } \\
\text { berdampak positife terhadap kesehatan } \\
\text { alat reproduksi. }\end{array}$ & $\begin{array}{c}6 \\
(15 \%)\end{array}$ & $\begin{array}{c}11 \\
(27,5 \%)\end{array}$ & $\begin{array}{c}9 \\
(22,5 \%)\end{array}$ & $\begin{array}{c}13 \\
(32,5 \%)\end{array}$ \\
\hline 7. & $\begin{array}{l}\text { Mencegah munculnya keputihan dan } \\
\text { bau tidak sedap. }\end{array}$ & $\begin{array}{c}6 \\
(15 \%)\end{array}$ & $\begin{array}{c}25 \\
(62,5 \%)\end{array}$ & $\begin{array}{c}6 \\
(15 \%)\end{array}$ & $\begin{array}{c}3 \\
(7,5 \%)\end{array}$ \\
\hline 8. & $\begin{array}{l}\text { Merasa malu untuk memeriksakan } \\
\text { ketidaknyamanan padaorgan intim. }\end{array}$ & $\begin{array}{c}12 \\
(30 \%)\end{array}$ & $\begin{array}{c}17 \\
(42,5 \%)\end{array}$ & $\begin{array}{c}7 \\
(17,5 \%)\end{array}$ & $\begin{array}{c}4 \\
(10 \%)\end{array}$ \\
\hline 9. & $\begin{array}{l}\text { Selalu mencatat jadwal mentruasi setiap } \\
\text { bulannya. }\end{array}$ & $\begin{array}{c}9 \\
(22,5 \%)\end{array}$ & $\begin{array}{c}17 \\
(42,5 \%)\end{array}$ & $\begin{array}{c}10 \\
(25 \%)\end{array}$ & $\begin{array}{c}4 \\
(10 \%)\end{array}$ \\
\hline 10. & $\begin{array}{l}\text { Tidak mengkonsumsi obat anti nyeri } \\
\text { ketika mengalami nyeri pada saat } \\
\text { menstruasi. }\end{array}$ & $\begin{array}{c}11 \\
(27,5 \%)\end{array}$ & $\begin{array}{c}9 \\
(22,5 \%)\end{array}$ & $\begin{array}{c}13 \\
(32,5 \%)\end{array}$ & $\begin{array}{c}7 \\
(17,5 \%)\end{array}$ \\
\hline
\end{tabular}

Table 4 Distribusi responden berdasarkan jawaban terhadap kuisioner mengenai tindakan perempuan dalam perawatan kebersihan alat reproduksi pada saat menstruasi

\begin{tabular}{|c|c|c|c|}
\hline No & Pertanyaan & Ya & Tidak \\
\hline 1. & $\begin{array}{l}\text { Apakah anda selalu mencuci tangan sebelum dan sesudah } \\
\text { memegang vagina? }\end{array}$ & $\begin{array}{c}38 \\
(95 \%)\end{array}$ & $\begin{array}{c}2 \\
(5 \%)\end{array}$ \\
\hline 2. & Apakah anda mengganti pembalut 2-3 kali sehari. & $\begin{array}{c}36 \\
(90 \%)\end{array}$ & $\begin{array}{c}4 \\
(10 \%)\end{array}$ \\
\hline 3. & Apakah anda mengganti celana dalam 1 kali sehari? & $\begin{array}{c}3 \\
(7,5 \%)\end{array}$ & $\begin{array}{c}37 \\
(92,5 \%)\end{array}$ \\
\hline 4. & Apakah anda sering menggunakan cairan pembersih vagina? & $\begin{array}{c}29 \\
(72,5 \%)\end{array}$ & $\begin{array}{c}11 \\
(27,5 \%)\end{array}$ \\
\hline 5. & Apakah anda membersihkan vagina dengan air yang bersih? & $\begin{array}{c}40 \\
(100 \%)\end{array}$ & $\begin{array}{c}0 \\
(0 \%)\end{array}$ \\
\hline 6. & $\begin{array}{l}\text { Apakah anda membersihkan vagina dengan cara dari arah } \\
\text { belakang ke depan? }\end{array}$ & $\begin{array}{c}10 \\
(25 \%)\end{array}$ & $\begin{array}{c}30 \\
(75 \%)\end{array}$ \\
\hline 7. & $\begin{array}{l}\text { Apakah anda selalu menggunakan tissue/handuk untuk } \\
\text { mengeringkan vagina? }\end{array}$ & $\begin{array}{c}35 \\
(87,5 \%)\end{array}$ & $\begin{array}{c}5 \\
(12,5 \%)\end{array}$ \\
\hline 8. & $\begin{array}{l}\text { Apakah anda memakai celana dalam yang ketat saat } \\
\text { menstruasi? }\end{array}$ & $\begin{array}{c}15 \\
(37,5 \%)\end{array}$ & $\begin{array}{c}25 \\
(62,5 \%)\end{array}$ \\
\hline
\end{tabular}




\begin{tabular}{|l|l|c|c|}
\hline 9. & $\begin{array}{l}\text { Apakah anda menggunakan celana dalam yang bersih yang } \\
\text { terbuat dari bahan katun? }\end{array}$ & $\begin{array}{c}20 \\
(50 \%)\end{array}$ & $\begin{array}{c}20 \\
(50 \%)\end{array}$ \\
\hline 10. & $\begin{array}{l}\text { Apakah anda pernah mencukur sebagian dari rambut } \\
\text { kemaluan untuk menghindari kelembapan yang berlebihan? }\end{array}$ & $\begin{array}{c}20 \\
(50 \%)\end{array}$ & $\begin{array}{c}20 \\
(50 \%)\end{array}$ \\
\hline
\end{tabular}

Table 5 Distribusi Responden Berdasarkan Pengetahuan Remaja Putri

\begin{tabular}{|c|c|c|c|}
\hline No & Pengetahuan & Frekuensi & Persentase \% \\
\hline 1 & Baik & 32 & 80 \\
\hline 2 & Cukup & 8 & 20 \\
\hline 3 & Kurang & 0 & 0 \\
\hline & Total & 40 & $100 \%$ \\
\hline
\end{tabular}

Table 6 Distribusi Responden Berdasarkan Sikap Remaja Putri

\begin{tabular}{|c|c|c|c|}
\hline No & Sikap & Frekuensi & Persentase $\%$ \\
\hline 1 & Positif & 29 & 72,5 \\
\hline 2 & Negatif & 11 & 27,5 \\
\hline & Total & 40 & $100 \%$ \\
\hline
\end{tabular}

Table 7 Distribusi Responden Berdasarkan Tindakan Remaja Putri

\begin{tabular}{|c|l|l|l|}
\hline No & \multicolumn{1}{|c|}{ Tindakan } & \multicolumn{1}{c|}{ Frekuensi } & \multicolumn{1}{c|}{ Presentase \% } \\
\hline 1 & Dilakukan & 29 & 72,5 \\
\hline 2 & Tidak Dilakukan & 11 & 27,5 \\
\hline \multicolumn{2}{|c|}{ Total } & 40 & $100 \%$ \\
\hline
\end{tabular}

\section{Pembahasan}

Hasil penelitian tentang perilaku remaja putri dalam perawatan kebersihan alat reproduksi pada saat mentruasi ditinjau dari aspek pengetahuan pada remaja putri yang berpengetahuan baik sebanyak 32 responden $(80 \%)$, berpengetahuan cukup sebanyak 8 responden (20\%), dan berpengetahuan kurang sebanyak 0 responden (0\%). Menurut asumsi penelitian bahwa pengetahuan remaja putri di SMP Swasta AL-HIKMAH Wilayah Marihat Bandar Kabupaten Simalungun berpengetahuan baik, dikarenakan informasi yang diterima, baik dari orang tua maupun dari pendidikan serta sarana dan media informasi. Berdasarkan hasil penelitian tentang perilaku remaja putri dalam perawatan kebersihan alat reproduksi pada saat mentruasi ditinjau dari aspek sikap pada remaja putri bersikap positif sebanyak 29 responden $(72,5 \%)$, dan bersikap negatif sebanyak 11 rsponden $(27,5 \%)$.

Menurut asumsi penelitian bahwa sikap remaja putri di SMP Swasta AL-
HIKMAH Wilayah Marihat Bandar Kabupaten Simalungun bersikap positif, dikarenakan informasi yang diterima,baik dari orang tua maupun dari pendidikan serta sarana dan media informasi. Berdasarkan hasil penelitian tentang perilaku remaja putri dalam perawatan kebersihan alat reproduksi pada saat mentruasi ditinjau dari aspek tindakan pada remaja putri yang tindakan dilakukan sebanyak 29 responden $(72,5 \%)$, dan yang tindakan tidak dilakukan sebanyak 11 responden (27,5\%). Menurut asumsi peneliti baik tindakan yang dilakukan remaja putri dalam perawatan kebersihan alat reproduksi Pada saat menstruasi di SMP Swasta Wilaya Marihat Bandar Kabupaten Simalungun. 


\section{Kesimpulan}

Dari 40 responden ditemukan pengetahuan remaja putri dalam perawatan kebersihan alat reproduksi pada saat menstruasi sebagian besar pada tingkat pengetahuan baik sebanyak 32 responden (80\%). Dari 40 responden ditemukan sikap remaja putri dalam perawatan kebersihan alat reproduksi pada saat menstruasi sebagian besar pada sikap positif sebanyak 29 responden $(72,5 \%)$. Dari 40 responden ditemukan tindakan remaja putri dalam perawatan kebersihan alat reproduksi pada saat menstruasi sebagian besar tindakan dilakukan sebanyak 29 responden $(72,5 \%)$. remaja putri agar meningkatakn prilaku dan mencari informasi tentang perawatan kebersihan alat reproduksi pada saat menstruasi dengan mengikutin programprogram atau penyuluhan yang diadakan oleh tenaga kesehatan atau balai kesehatan. meningkatkan pelayanan kesehatan dalam membantu remaja putri agar dapat memahami secara mendalam tentang perawatan alat reproduksi.

\section{Referensi}

Alli J.A.O., Okonko I.O, Odu N.N., K. A. F. and N. J. C. (2011). Detection and prevalence of Candida isolates among patients in Ibadan, Southwestern Nigeria. Journal of Microbiology and Biotechnology Research.

BKKBN. (2013). Kesehatan Reproduksi. Jurnal Populasi. https://doi.org/2101018
Farizal, J., \& Dewa, E. A. R. S. (2017). Identifikasi Candida Albican pada Saliva Wanita Penderita Diabetes Melitus. Jurnal Teknologi Laboratorium. https://doi.org/10.1902/jop.2004.75.5. 663

Larasati, T., \& Alatas, F. (2016). Dismenore Primer dan Faktor Risiko Dismenore Primer pada Remaja. Jurnal Majority.

Manuaba, I. (2010). Memahami Kesehatan Reproduksi Wanita. Jakarta: Arcan.

Septadina, \& Seta, I. (2015). Upaya Pencegahan Kanker Serviks Melalui Peningkatan Pengetahuan Kesehatan Reproduksi Wanita Dan Pemeriksaan Metode Iva (Inspeksi Visual Asam Asetat) Di Wilayah Kerja Puskesmas Kenten Palembang. $J$.

Sessa, F. M. (2015). Adolescence. In Encyclopedia of Mental Health: Second Edition. https://doi.org/10.1016/B978-0-12397045-9.00055-0

Thapar, A., Collishaw, S., Pine, D. S., \& Thapar, A. K. (2012). Depression in adolescence. The Lancet. https://doi.org/10.1016/S01406736(11)60871-4

Viner, R. M., Ozer, E. M., Denny, S., Marmot, M., Resnick, M., Fatusi, A., \& Currie, C. (2012). Adolescence and the social determinants of health. The Lancet. https://doi.org/10.1016/s01406736(12)60149-4 